\title{
Towards an Anthropological Insight of Sustainable Tourism
}

\begin{abstract}
By Maximiliano Korstanje*
"The tragedy of the commons is involved in population problems in another way. In a world governed solely by the principle of dog eat dog - if indeed there ever was such a world- how many children a family had would not be a matter of public concern ... it is a mistake to think that we can control the breeding of mankind in the long run by an appeal of conscience..."

(Hardin 1968: 1246)

This essay review discusses to what extent tourism transforms environment as a vehicle towards development. Not only we review some of the specialized literature in sustainability issues, but also proposes a clear explanation why in spite of efforts to expand poverty relief, things came out worse than planned. This happens because sustainability as it was designed in the cabinet of tourism experts, is based on rationality which is the perverse core of capitalism. Citing Ingold's outcomes unless society passes from a dwelling to relational perspective, the problem of global warming is far from being solved.
\end{abstract}

Keywords: Ecology, Tourism, Global Ecology, Pollution, Capitalism, Mobilities.

\section{Introduction}

Tourism surfaced in the mid of twentieth century as a combination of different factors, which were integrated into the consolidation of global material forces. These forces not only accelerated the process of globalization, but also the technological background for the rise of modern tourism (Towner 1985, Ousby 1990, Gassan 2008). In the western imaginary, the quest of novelty and escapement occupied a central position and most certainly, it cannot be limited to the tourism industry. In fact, leisure travels, adventures, and discoveries played a leading role in the configuration of an archetypical character which is enrooted in ancient myths, legends and stories. As Krippendorf puts it, tourism can be understood as an ancient rite of passage which revitalizes the psychological frustrations (Krippendorf 2010, Thirkettle and Korstanje 2013). This suggests that tourism is adjusted to the local environment as well as the economic matrix of each society. The point was originally formulated by Jafar Jafari (1990, 2005) when he thought his four platforms model (advocacy, cautionary, adaptancy and scientific platforms). With the benefits of hindsight, Jafari was concerned on the effects of tourism over the environment. Centered on the concern, tourism exploits local resources, it is necessary to implement programs of protection that leads the community to take coactive policies towards sustainability. Although from its

\footnotetext{
*Senior Lecturer. Economics Department, University of Palermo, Buenos Aires, Argentina.
} 
onset, tourism and sustainability were inevitably entwined, no less true is that the Academy does not agree to what extent tourism industry fosters environmental protection or simply mutates towards a new way of economic exploitation over local communities. In this respect, some voices argue that tourism, when it is regulated by the government, leads towards economic prosperity and fair wealth distribution. For other scholars, instead, tourism affirms the center-periphery dependency. This conceptual paper summarizes the problems and limitation of sustainable tourism as it has been adopted in Latin America. The economiccentered paradigm focuses exclusively on the profits of the tourism industry, as well as its material benefits. Not surprisingly, the world is divided into two sides, the sustainable and unsustainable economies. This opened the doors towards a new division of labor where some global southern economies as Brazil, Argentina, South Africa, Australia and New Zealand take the lead in sustainable issues while the Global North rejects the possibility to reach consensus to reduce the greenhouse gases. This novel form of dependency reminds that industrial nations have further capacities to emit further quotas of greenhouse gases in comparison to agrarian economies. This work discusses critically to what extent the idea of sustainability reinforces a long-dormant discourse oriented to legitimate the interests of the ruling elite. The goals of the work are twofold. Firstly it summarizes the history of heritage and its intersection with the colonial rule. Secondly, the figure of the relational perspective is introduced for reaching a fresh alternative reading on the problem of sustainability (Korstanje 2018).

\section{Jafar Jafari and the Four Platforms}

As stated in the earlier section, Jafar Jafari was originally concerned about the impacts of the tourism industry in the environment. He coins the term "scientifization of tourism" to denote the manipulation and rationalization of local resources within certain objectivity which is functional to efficient planning. To put the same in his terms,

"The purpose of this theoretical work is to provide retrospective and perspective view on tourism's scientific journey. More specifically, the aim is to identify some of the past conditions that have helped tourism to assume its present scholarly dimension and depth; to sketch the formation of this landscape of knowledge to selectively extract from this context emerging central socioeconomic issues; to suggest research crossroads for advancing in new frontiers; to sample the richness of the state of knowledge ... that in turn can guide present and future planning and operation of this diverse mega-industry. Conceptually informed and practically enriched sustainable strategies, now rooted in this body of knowledge, can and will benefit those directly and indirectly involved in tourism.." (Jafari 2005: 28).

Emulating a cyclical logic, Jafari toys with the belief that tourism gradually evolves in four distinguishable stages. The advocacy platform signals to the economic benefits and advantages generated by the tourism industry and foreign investment in the local communities. Stakeholders often can enrich the local 
economy when foreign and local investors coordinate efforts in the generation of fairer wealth distribution. After the $60 \mathrm{~s}$ decade, however, some critical voices interrogated on the so-called material benefits tourism supposedly brought (Jenkins 1982, Mbaiwa 2005). In view of this, a new cautionary platform alerted on the negative effects of the tourism industry in the local environment. Contamination, pollution, poverty among many other maladies led specialists and policy-makers to question the idealized vision of tourism. A third platform is born in the middle of the 80 s decade, which is termed as "adaptancy platform". This position weights the advantage and disadvantage of the industry stressing in the ethical responsibility of stakeholders to protect the local resources. Jafari goes on to write, "The prescribed strategies have variously been known as agro-tourism, appropriate tourism, community-based tourism, controlled tourism, cottage tourism, cultural or ethnic tourism, ecotourism, farm tourism, green tourism... the list is still growing with no tourism even named as an alternative by itself". In general, the adaptancy platform argues that the forms are community centered, employ local resources, are relatively easier to manage, are not destructive benefit host and guest groups alike, and even improve communication between them (Jafari 2005: 31).

The three above-mentioned stages paved the ways for the emergence of a scientific perspective which crystallized into a purer form of evolution independent from any subjective viewpoint. The other platforms were occupied in the study of tourism through its direct and indirect effects in the environment, but rather "the scientific platform" rested on the principle of objectivity as more evolved and superior form of knowledge. Jafari ponders "the scientifization of tourism" as a path towards a climate of professionalization, which associated with scientific research, helps policy-makers in their decision making processes. Jafari acknowledges that tourism should be studied as a well-integrated system whose parts harmonically worked together and interconnected. He was convinced by the belief that the tourism industry - as well as the scientific platform - accompany local communities towards a climate of prosperity and sustainability.

"The above discussion on the four platforms, the transformative forces or catalyst, the text, and context of these in structuring and shaping training and education efforts and outlooks, provide informative retrospective and ongoing insights on tourism - both as a realm of concepts and as a field of operations. This may now be coupled with a fresh insight beyond the present scholarly footholds and operational matters, toward scientific and developmental horizons ahead" (Jafari 2005: 38).

The intersection of tourism and sustainability was not only present in the early Jafari's texts but also was adopted by his followers as a doctrine of the discipline to date. Although Jafari clarifies that each stage is not unilateral nor evolutive but also alternates with others his supporters singled out his legacy in the following axiom: when tourism is adopted by local communities a synergy of local and external forces converge. This convergence invariably should prosper in a democratic atmosphere. The rich (developed) nations have the obligation to help under-developed economies. In so doing, tourism channels the local and financial resources to create a sustainable industry that alleviates poverty. While rich 
countries often manage the financial assets to protect the earth, pour nations adopt the precautionary platform" in order for their resources not to be degraded. In Jafari's development, the center-periphery dependency is not tackled off and little attention is paid on the role of international organizations as the World Bank and IMF. As Esteva brilliantly observed, the IMF and World Bank supposed that the indiscriminate loans will bring development to the world. The development theory not only failed in its mission of poverty relief but in some conditions, it aggravated the dependency of the third world. When the development programs failed to boost local economies, their exegetes alluded to the cultural factor as an illustrative explanation that speaks us of the incompatibilities of non-western cultures to embrace "the western rationality". Social maladies such as internal conflict, political instability and even corruption were highlighted as the main causes that impeded the development of some non-western nations. Once again, culture is ideologically invoked to divide the world in two. The dichotomy civilizeduncivilized cultures set the pace to a "developed-undeveloped" typology (Esteva and Prakash 1998, Sachs 1997, Esteva and Babones 2013, Pieterse 2000).

\section{The Theory of Development Explained with Clarity}

In a valuable investigation entitled Development and Social Change, P. McMichael (2012) reminds the intersection of colonialism and development as a barrier towards genuine changes to achieve a fair distribution of wealth. Instead of focusing on the protection of the state, as it has been formulated by development theories, globalization emphasizes on "free-market" as the ideological conduits of politics. The protection of interests of global powers consists not only in securing the food production (in the south) to be exported to North but also in the set of loans to keep "the market integration". The key factor of neo-liberalism is "governance", which means the coordination of NGOs by accessing information and material resources to fulfil the gaps left by "failed-states". Today, corporate outsourcing is the crucial point Market used to determine the contours of states. His main thesis is that Europe, by the introduction of "colonialism", established an ideological background for legitimizing their submissions to its overseas colonies. The exploitation of the non-European "Others" had a pervasive nature. The process of decolonization, centuries later, witnessed the rise of demands of the periphery in order for central powers to allow an autonomous government. The rights of democracy became in a universal claim. McMichael explains that imperial powers alluded to the theory of "development" to maintain the old colonial borders. Now violence sets the pace to financial dependency (McMichael 2012). The WWII (Second World War) end conjoined to Truman's administration led the United States to implement a wide range credit system to save the world from Communism. This program mushroomed to become in the development theory. However, this financial aid brought modification in the system of agriculture to more intensive methods. This ruined the condition of farmers who were pressed to migrate to larger urban cities. Furthermore, the imposition of new borders post-WWII forced many ethnicities to live with others under the 
hegemony of nation-state. This resulted in a lot of ethnic cleansing, conflicts and warfare that obscured the original ends of financial aid programs issued by the IMF or World Bank. Undoubtedly, the inconsistencies of the World Bank in administering the development-related programs not only were admitted but also it woke up some nationalist reactions in the non-aligned countries. To restore the order, a new supermarket revolution surfaced: globalization (McMichael 2012).

This stage, characterized by a decentralized production, undermined the barriers of nation-states globalizing investments in those countries where working condition were more convenient for capital-owner. In this vein, two alarming situations were found. An increase in the unemployment and the decline of unionization in the North was accompanied by the arrival of international business corporations seduced by the low-cost of workers in the South. Last but not least, the problem of ecology was not a minor issue. Ecological emergencies accelerated by global warming not only ruined many agrarian economies but provoked a wider forced-migration as never before (McMichael 2012).

\section{From the Ecocide to the Sustainability of Tourism}

In a seminal book, which entitles Ecocide: a short history of the mass extinction of species, Franz Broswimmer calls the attention on the idea of progress, which lead Occident to a technological background that materialized a rapid transformation of the environment. However, as he puts it, this career towards progress was possible thanks to the introduction of an obtrusive technique that created a real "ecocide". His argument says that westerners are enmeshed into a paradoxical situation. While lay-citizens overtly declare their concern for pollution and environmental degradation, fewer courses of actions are systematically taken without mentioning that no efforts to reduce the greenhouse gases are concreted. Broswimmer conceptualizes the relations of humankind with nature in three stages. The first facet is marked by the appearance of language (60.000 millions of years ago). Secondly, the economic shortage moved to homosapiens to expand their presence across the world (13.000 B.C.). The industrial revolution cemented the hegemony of Western civilization and its rationality over other forms of knowledge. In so doing, the technological breakthrough made from this world a safer place but at a high cost. Mankind constructed a cultural bubble which inserted separated from nature, which was ideologically conceptualized as a mere resource to be commodified, processed and sold in the liberal market (Broswimmer 2002). The ecocide results from the excess of rationality which subordinates the nature to the logic of capitalism, as Broswimmer adheres. Spanish philosopher Adela Cortina argues convincingly that the ethics of consumption are doomed to the failure since citizens are insensitive to the Other's suffering. Under what basis the future is important for mankind when really the well-being of their members passes without serious attention?

In this vein, Cortina proffers a moral reformation to accelerate the necessary changes towards a more sustainable planet. As she notes, each person develops a threshold of desirability which expresses its comfort. Ordinary people are often 
accustomed to following standardized practices and behaviour which impede the real change. Hence, the climate change far from being considered as a serious threat seems to be commodified and offered in form of a great spectacle (Cortina 2003). Jean Baudrillard termed this as "the Spectacle of Disaster" in his different works (Baudrillard 1995), while Naomi Klein dubbed it as "the doctrine shock" (Klein 2007). Both positions reflect the same issue. The sense of risk which is mediatically imposed to the audience speaks us of a near future, which never takes the room in reality. From the future, the imperative rests on the axiom that a new cultural entertainment industry, which combines an extreme psychological fear with the needs of exception, commoditizes the other's pain in forms of spectacles (Korstanje 2016). This begs a more than interesting question, is tourism part of the solution or the problem?

Bob McKercher (1993) lamented that the western rationality, as well as the obsessions of policy-makers for the precautionary platform, would engender further risks that place the tourist system in jeopardy. Per McKercher, this obviously happens because ecology appears to be a concept very hard to grasp. In the name of ecology or sustainability, weak economies are subordinated to the interests of the stronger ones. It is important not to lose the sight of the fact that financial programs fostered by IMF (International Monetary Fund) and World Bank have failed, but a new eco-friendly wave emerged to re-educate to the next generations to keep a reasonable dialogue with nature (Taylor and Carson 2010).

From this viewpoint, dessert or limited resources zones need from ecology to gain attractiveness and of course, in doing so tourism plays a crucial role. Sometimes the underdevelopment is considered as a lack of planning and training. Education not only solves many problems in the adoption of sustainable tourism but also allows improving the coordination of different stakeholders' interests (Farrell and Runyan 1991, Jollife 2005, Hipwell 2007, Stubbs and Cocklin 2008, Muller and Weber 2008, Contini et al. 2009). In addition, Skanavis and Giannoulis (2010) claim that Greece would have not adopted a strong pro-environmental policy to encourage tourism. Particularly, there would be no vision aimed at integrating environmental interpretation with the practitioner's practices. These scholars consider that accurate and effective interpretation of ecology, as well as monitoring, entails positive impacts for the community (Skanavis and Giannoulis 2010). Equally important, the already-established literature suggests that neither the precautionary nor advocacy platforms did the correct thing in the struggle against climate change. Instead of regulating as the main option, It is necessary to find a new segment of tourism, as "cultural tourism or creative tourism" as new forms of sustainable consumption (Okello and Yerian 2009, Mamadi 2004, Hjalager 2000, Tsaur et al. 2006 Ambrosie 2010). The consumption should not be divorced from the necessary (natural) background to perform it. To put the same in other terms, tourism commoditizes nature (which is sublimated in the tourist-gaze) compromising the natural resources. The ecological dilemma reminds two important things. On one hand, these natural resources may be very well replicated whether a sustainable way is widely adopted. On another, without an environment there is no tourism (Bramwell and Lane 1993, Gossling 2000). To some extent 
exegetes of sustainable tourism emphasizes on the importance of an accurate diagnosis, which should be adjusted to what each community needs.

In a recent book, for example, three authoritative voices in the theme as Michael Hall, Stefan Gossling and Daniel Scott suggest that tourism is not good or bad, but a simple instrument which should be oriented to promote local welfare. Since today "global warming" seems to be one of the most urgent problems, western should tackle, remains in academy certain myopia to understand the urgency of this slippery matter. As the main threat of capitalist societies, "global warming" not only may affect seriously the global trade among nations but the economic resources as well. What should policy-makers do in this respect? Occident urges to exploit its current technology to monitor the effects of global warming, reminding that a more efficient adaptive response should be prioritized as a policy of the state. They, authors, understand that capitalism as well as its system of production cannot be abandoned. Therefore the needs of adaptation is of paramount importance in the planning process. The global warming for Hall, Gossling or Scott, does not mean a direct result of the expansion of capitalism, but a glitch to fix. What they ignore, is that "global warming" was produced by the same cultural values (as rationality) they defend.

Needless to say, the above-noted argument is shared by countless scholars in the fields of tourism sustainability. One of the main obstacles tourism-related scholars may not overcome is related to the excess of trust in technology and rationality as vital factors for a solution. Secondly, sustainability as a cultural project excludes the presence of humankind from the territory to be protected. Humans, in the post-capitalist ideology, are not part of nature but external administrators who through their rationality can identify and reverse those risks or problems that jeopardize the environment (Korstanje 2018). This is exactly the dilemma of the theory of governance, which holds the thesis that authorities should find the correct steps and policies to intervene in the territory in order for the organic image of the destination to be preserved. Although there are some glitches, which in a climate of contingency, may emerge, the western rationality supported by the current technology- obtains a rapid solution. To set an example, by adopting new sources of energy the problem of climate change can be finally overcome (Dinica 2009). Over the recent years, some scholars doubted on faith in technology reminding that climate change often recreates the conditions to an irreversible situation. Paradoxically, the precautionary principle learned us that while some risks are easily neutralized other more dangerous surface. The climate change has arrived to say, in which case, humankind debates between intervening directly the causes or simply emulating some adaptive measures (Becken 2008, Weaver 2011, Scott and Becken 2010). McGranaham (2011) exerted a radical criticism on these two stances because -as he thinks- the ecology-related research associates to the profit-maximization which is proper of the private market. Secondly, the current ecological paradigm shows no fewer problems to understand or situate human presence. In the protected parks, the human presence is limited or prohibited. Third, humans often dissociate what they overtly say and finally do. This was probed in some works oriented to study the dominant discourse in tourists about "the future of climate change". While tourists were seriously 
worried about the future of the planet, they did not start any concrete step to change the situation (Becken and Hay, 2007, Scott et al. 2012). In a recentlyreleased book, Tzanelli (2019) clarifies that scholars need to dissociate mobilities design and the mobilities justice. While the former signals to the fabrication of destinations through the cinematically-inspired stimulation, the latter refers to its real or imagined consequences and effects. To some extent, mobilities justice may be understood as the possibilities each citizen to reach "an appropriate mobility capital". As the first entry in this philosophical debate, she introduces the neologism "atmospheric attunement" to frame not only the scholars' cosmologies which lead them to multisensory interpretations of reality (scientific paradigm) but the countless ways subjects move through their affective world (subjectivity). While lay-people want the material benefits of tourism, less tolerant they are to the produced shifts in our local environment. It is important not to lose the sight of the fact that cities concentrate human and capital factors in a form of "phantasmagoric factory" at the time the countryside is symbolically re-elaborated as a romantic form of sublimation which helps the alienated citizen to redeem itself through consumption. As Tzanelli puts it, the efforts put to avoid the environmental degradation says little on how the beautiness as a concept is culturally constructed. Given the problem in these terms, West has a problem to understand the different "Other". Based on a critical reading of the post-colonial literature as the main theoretical framework, Tzanelli calls the attention that the expression of discontent (against tourism) should re-classified in three distinguishable forms: a) epistemic misalignment, which mainly located in post-colonial territories, combines an adaptive behaviour with a combative attitude; b) hostipitality which connotes a hostile position against strangers ritualizing a type of new ethnonationalism, and c) post-industrial disobedience which redeems differences and rivalries in the cinematic screen (Tzanelli 2019).

This begs more than the interesting question is feasible to work for sustainable tourism? is sustainability viable in an hyper-globalized world?

\section{Discussing the "Dwelling Perspective"}

To respond to the questions formulated in the earlier section, it is necessary debate the idea of the dwelling perspective in Tim Ingold. In his book, The Perception of Environment Ingold (2000) presents a more than thorny question. Is the sustainable premise a manifest impossibility?

Societies construct some ideological dispositions oriented to understand the Other while at the same time, an axis of authority is internally imposed. The idea of an "exemplary center" associates to the presence of a dangerous periphery. In this context, the alterity should be labeled and framed in order for a state of internal security to be achieved. The dilemma of authenticity dominates the politics of the tribe. At the time people believe they are authentic, they feel the others lie. Museums and Zoos, following this explanation, serve as sanctuaries of authenticity where animals or artefacts should be protected (Ingold 2000, 2011). The success of capitalism consists in the creation of binomials such as binomials such as culture/wilderness, leisure/work, authentic/inauthentic. Unlike hunters/ 
gathers, the environment for West is conceived as something external to human order; in other words, the self inhabits a hostile place which should be domesticated by its culture. Human beings are a pretty different agent than animals. This allowed us to intervene to our discretion manipulating our dwelling in nature. Unlike hunters and gatherers, westerners developed a sedentary form of production, which links them to a specific-contextualized soil. The invention of the chair splits the man from his environment but what seems to be more important, the evolution of science legitimized a philosophical separation of the self from its environment. Taking his cues from Gibson, Ingold accepts that neither philosophers nor social scientists have interrogated on the ideological nature of western rationality. The debate revolving around sustainability does not comprehend the human presence, affirming our disengagement from nature. The supremacy of the instrumental reasoning not only is valorized in the eco-friendly paradigm but also places "consciousness" as the main criteria of supremacy. Nature is divided into two, intelligent and unintelligent life. As mutually incompatible, humankind and nature are seen as different entities. The preserved and ecological parks ban the human presence and not surprisingly, the mainstream cultural values of capitalism are never questioned. Ingold cites the sample of hunters-gatherers who see the environment in the lens of a relational perspective. These nomad groups not only do not need the surplus of food (to be stocked) but also connects with nature as something given to their survival (Ingold 2000). In this way, animals and men are integrated into the same all-encompassing cosmology. In his book Being Alive Ingold (2011) reminds that westerners have developed a "dwelling perspective" which re-conceptualizes human existence through the technology fabricated to change the environment. Nature can be expropriated whether the man improves it. The external world cannot be therefore understood without rational reasoning. Having said this, modern science is no other thing than an attempt to domesticate the uncertainty of the environment through the articulation of programs, protocols and the sense of objectivity. The separation between subject and objects started by the invention of the chair, Ingold adds. It has been created to confer dignity and authority to the sitter; to separate humans from animals. At some extent, if further attention is paid to how people travel, two assumptions should be done. Travelers do not move unless by a machine, whose conforms allows us to be sited while moving. Secondly, travels were commercially adopted by the European elite during the 18th century while blue-collar workers were subject to walk. The pedestrian practices stigmatized to lay people. The knowledge was given only to those who displace to other places to know further on the customs and lives of others. These inequalities between those who would be able to travel a long distance and those who would be unable to do that pave the ways for the advent of capitalist hegemony. The fact that some groups are mobile while others are not being conducive to a discourse of domination. To be more explicit, the author goes on to say:

We have already seen how the practices of destination-oriented travel encouraged the belief that knowledge is integrated not along paths of pedestrian movement but through the accumulation of observations taken from successive point of rest. Thus we tend to imagine that things are perceived from stationary 
platform, as if we were sitting on a chair with our legs and feet out of action. To perceive a thing from different angles, it is supposed that we might turn it around in our hands, or perform an equivalent computational operation in our minds. But in real life, for the most part, we do not perceive things from a single vantage point, but rather by walking around them (Ingold, 2011: 45).

The creation of maps and geography are signs of dissociation between walking and travelling. The traveler who knows the path do not need a map. Recurring to watch a map only when travelers are unfamiliar with the topography of territory. The discussion with Heidegger respecting to what Ingold calls, "the dwelling perspective" deserves considerable attention. The British anthropologist reminds that anthropology is based on the premise some forms of "humans build" are a projection from the environment. This alludes to think that space should be built (symbolically created) to be dwelled, as both were two separate facets of living. In order for nature to be safe, also no human intervention should be achieved. At the opposite, Ingold proposes a relational view of ecology to stress a new fresh way of conceiving ecology. The modern society must pass from a dwelling to a relational perspective. Since Humans inhabit the space at the same time they live, the dwelling perspective should set the pace to a much broader cosmology respecting to the environment. Hunters and gatherers take the life of animals only to survive. Like their ancestors, they venerate animals as brothers, as protectors whose flesh ignites the cycles of life. Any attempt to monopolize hunting activity denotes in the fact that Gods withhold animals leading the community to starvation and extinction. This cosmology is based on a relational perspective that does not differentiate between humans and animals. The founding parents of anthropology created the idea of culture to separate the European project from the non-western "Others" (Harris 2001, Racdliffe-Brown 1940, Mauss 2002, Malinowski 2013). The notion of travels was a symbolic conquest where Oceania or the Americas were seen as vast places to dwell, domesticate and civilize. The concept and division of labor were of significant importance because it introduced trust for the progress. Hence, as Ingold writes, technology, intelligence, the habit of dwelling and the concept of landscapes have been socially constructed to expand the belief that reason, which is only human, can be expressed by means of language. Here two assumptions finally should be done. On one hand, the dwelling perspective, which was encapsulated in modern anthropology from its inception, nourished a dichotomy between protection and extinction. The native cultures were defined as entities petrified in a pre-stage towards civilization, in the same way, the pre-modern Europe was. The first ethnologists envisaged that these pre-modern cultures would be invariably in the bias of disappearance. For that, the job of the first fieldworkers associated to pick up and repatriate all artefacts to the European museums. To say the same in other terms, the interests for the other was culturally subordinated to its reversible inferiority in a Darwinist world where the big fish eats the small fish. On another hand, the capitalist discourse reiterated the myth that leisure liberates the modern man from the work. The efficacy of capitalism - to be reproduced- rested on its capacity to control commodities and workers. While the former is marked by the exchange price which is fixed by the market, the later depends on its mood 
adapted to consume. Lay-people are workers who dispose of their bodies to fabricate goods they ultimately are forced to consume in their free-time. At the least, the notion that subjects need to work to rest appears to be an ideological disposition that legitimated capitalism as well as "the dwelling perspective" over the recent centuries (Ingold 2011). So the question is to what extent the modern tourism industry is part of the problem or the solution?

\section{Conclusion}

After further criticism on the theory of development, as well as the idea that tourism revitalizes economy and sustainability of nations, this essay review dissected in depth the ideological nature of capitalism dividing the world in periphery and center. The first section brought the legacy of Jafari into the foreground as well the obsession of his followers for sustainability. The second, rather, focused on the ideological components that historically formed the development theory. Based on McMichael's contributions, it is important not to lose the sight of the fact that the theory of development and the colonial rule are inextricably intertwined. The third section not only goes through the philosophical debate regarding climate change but also revolves around how the notion of sustainability was adopted by tourism-related scholars. Lastly, the paper deals with the relational paradigm and the impossibility of the capitalist system to change its economic means of production towards a more sustainable tourism. In consonance with Tim Ingold, the argument held in this conceptual research explains the reasons why lay-people feel "sustainability of tourism" remains an impossible project. One of the ideological core of capitalism consisted of introducing a rupture, which Ingold dubbed as "dwelling perspective", between humans and nature. This means that the ecological project not only is reserved for animals but exclude any human presence. Although efforts to make a more sustainable society prevails, if the mainstream cultural values of capitalism as extortion, instrumentality and exploitation should not be corrected, the possibilities tourism would be part of the problem, not the solution, turns out higher. This is not an attack to anyone or any theory, but a fresh alternative for researchers and academy correctly deciphers the complexity of ecology in the years to come.

\section{References}

Ambrosie L (2010) Tourism Enterprises and Sustainable Development: international perspectives on responses to the sustainability agenda. Tourism Management 31(6): 961-962.

Baudrillard J (1995) The Gulf War Did Not Take Place. Sydney: Power Publications.

Becken S (2008) Climate Change - Beyond the hype. Tourism Recreation Research 33(3): 351-353.

Becken S, Hay JE (2007) Tourism and Climate Change: Risks and Opportunities, Vol. 1. Clevendon: Multilingual Matters. 
Broswimmer F (2002) Ecocide: A Short History of the Mass Extinction of Species. London: Pluto Press.

Contini C, Scarpellini P, Polidori R (2009) Agri-tourism and rural development: The LowValdelsa case, Italy. Tourism Review 64(4): 27-36.

Cortina A (2003) For An Ethic of Consumption. Montevideo: Taurus.

Dinica V (2009) Governance for sustainable Tourism: a comparison of international and Dutch visions. Journal of Sustainable Tourism 17(5): 583-603.

Esteva G, Babones SJ (2013) The Future of Development: A Radical Manifesto. Bristol: Policy Press.

Esteva G, Prakash MS (1998) Beyond development, what?. Development in Practice 8(3) 280-296.

Farrell B, Runyan D (1991) Ecology and tourism. Annals of tourism Research 18(1): 2640.

Gassan RH (2008) The Birth of American Tourism: New York, the Hudson Valley, and American Culture, 1790-1830. Boston: University of Massachusetts Press.

Gössling S (2000) Sustainable tourism development in developing countries: Some aspects of energy use. Journal of Sustainable Tourism 8(5): 410-425.

Hardin G (1968) The tragedy of commons. Science 162 (3859): 1243-1248.

Harris M (2001) The Rise of Anthropological Theory: A History of Theories of Culture. Chesnut Creek: AltaMira Press.

Hipwell W (2007) Taiwan Aboriginal Eco-tourism: Tanayiku Natural Ecology Park. Annals of tourism Research 34(4): 876-897.

Hjalager AM (2000) Organisational ecology in the Danish restaurant sector. Tourism Management 21(3): 271-280.

Ingold T (2000) The Perception of Enviroment: Essays on Livelihood, Dwelling and Skill. London: Routledge.

Ingold T (2011) Being Alive. Essays on Movement, Knowledge and Description. London, Routledge.

Jafari J (1990) Research and scholarship: the basis of tourism education. Journal of Tourism Studies 1(1): 1-10.

Jafari J (2005) The scientifization of tourism. In V Smith and M Brent (eds) Host and Guest Revisited: Tourism Issues of the 21th Century, 28-41. New York: Cognizant Communications.

Jenkins CL (1982) The effects of scale in tourism projects in developing countries. Annals of Tourism Research 9(2): 229-249.

Jollife L (2005) Tourism and Development in Tropical Islands: political ecology Perspectives. Annals of tourism Research 32(1): 284-286.

Klein N (2007) The Shock Doctrine: The Rise of Disaster Capitalism. New York: Macmillan.

Korstanje ME (2016) The Rise of Thana Capitalism and Tourism. Abingdon: Routledge.

Korstanje M (2018) Mobilities Paradox: a critical analysis. Cheltenham, Edward Elgar.

Krippendorf J (2010) Holiday Makers. Abingdon: Routledge.

Bramwell B, Lane B (1993) Sustainable tourism: An evolving global approach. Journal of Sustainable Tourism 1(1): 1-5.

Malinowski B (2013) Argonauts of the Western Pacific: An Account of Native Enterprise and Adventure in the Archipelagoes of Melanesian New Guinea [1922/1994]. Abingdon: Routledge.

Mamadi M (2004) A Critical Analysis of the Effects of tourism on Cultural Representation: a case study from Leboeng. Dissertation, University of Western Cape, South-Africa. 
Mauss M (2002) The Gift: The Form and Reason for Exchange in Archaic Societies. Abingdon: Routledge.

Mbaiwa JE (2005) Enclave tourism and its socio-economic impacts in the Okavango Delta, Botswana. Tourism Management 26(2): 157-172.

McGranahan DA (2011) Indentifying ecological sustainability assessment factors for Ecotourism and trophy hunting operation on Private rangeland in Namibia. Journal of Sustainable Tourism 19(1): 115-131.

Mckercher B (1993) The unrecognized threat to tourism: Can tourism survive sustainability?. Annals of Tourism Research 14(2): 131-136

McMichael P (2012) Development and Social Change. Tousands Oaks: SAGE.

Muller H, Weber F (2008) Climate Change and Tourism, scenario analysis for the Bernese Oberland in 2030. Tourism Review 63(3): 57-71.

Okello MM, Yerian S (2009) Tourist Satisfaction in relation to attraction and implications for Conservation in the protected areas of the Northern Circuit, Tanzania. Journal of Sustainable Tourism 17(5): 605-625.

Ousby I (1990) The Englishman's England: Taste, Travel and the Rise of Tourism. Cambridge: Cambridge University Press.

Pieterse JN (2000) After post-development. Third World Quarterly 21(2): 175-191.

Racdliffe-Brown AR (1940) On social structure. The Journal of the Royal Anthropological Institute of Great Britain and Ireland 70(1): 1-12.

Scott D, Becken S (2010) Adapting to Climate change and Climate policy: progress, problems and potentials. Journal of Sustainable Tourism 18(3): 283-296.

Scott D, Hall CM. Stefan G (2012) Tourism and Climate Change: Impacts, Adaptation and Mitigation. Abingdon: Routledge.

Skanavis C, Giannoulis C (2010) Improving Quality of Ecotourism through advancing Education and Training of Greek Eco-tour guides: the role of training in environmental interpretations. Tourismos, An International Multidisciplinary Journal of Tourism 5(2): 49-68.

Sachs W (ed) (1997) Development dictionary, The: A guide to knowledge as power. London: Orient Blackswan.

Stubbs W, Cocklin C (2008) Teaching Sustainability to Business Students. Shifting mindsets. International Journal of Sustainability in Higher Education 9(3): 206-221.

Taylor A, Carson D (2010) Four wheels drive tourism and economic development opportunities for remote areas. Tourismos, an international Multidisciplinary Journal of Tourism 5(2): 69-85.

Thirkettle A, Korstanje ME (2013) Creating a new epistemiology for tourism and hospitality disciplines. International Journal of Qualitative Research in Services 1(1): 13-34.

Towner J (1985) The grand tour: A key phase in the history of tourism. Annals of Tourism Research 12(3): 297-333.

Tsaur S H, Lin Y, Lin J (2006) Evaluating Ecotourism sustainability from the integrated perspective of resource, community and tourism. Tourism Management 27(4): 640653.

Tzanelli R (2019) Cinematic Tourist Mobilities and the Plight of Development. Abingdon: Routledge.

Weaver D (2011) Can sustainable tourism survive climate change? Journal of Sustainable Tourism 19(1): 5-15. 
